Dagley, S., Dawes, E. A. \& Morrison, G. A. (1951). J. gen. Microbiol. 5, 508-515.

\title{
The Kinetics of Pyruvate Production by Aerobacter aerogenes
}

\author{
By S. DAGLEY, E. A. DAWES and G. A. MORRISON \\ The Department of Biochemistry, School of Medicine, University of Leeds
}

SUMMARY: Pyruvic acid accumulates in aerated cultures of Aerobacter aerogenes during logarithmic growth and disappears rapidly in the stationary phase. The amount accumulated depends upon the carbon source utilized, being greatest with glucose and malic acid and least with acetic acid, of the compounds studied. For aerated washed suspensions of cells trained to metabolize glucose, malate, fumarate or succinate respectively, the rates of pyruvate production for various substrates are in the order: rate in malate $>$ fumarate $>$ succinate $>$ acetate. Only cells trained to metabolize acetate produce pyruvate from acetate as fast as from succinate and fumarate. When ammonium salt solution is added to these suspensions accumulation of pyruvate ceases.

Rates of pyruvate production at various substrate concentrations by washed suspensions accord with a kinetic scheme in which pyruvate appears as a transitory intermediate in a reaction sequence. Results are not compatible with the existence of the tricarboxylic acid cycle in bacteria.

The operation of the tricarboxylic acid cycle in bacterial respiration has not been proved (Ajl \& Werkman, 1949), although a number of investigations carried out with Escherichia coli and Aerobacter aerogenes grown on simple chemically-defined media suggest that it may play a part in the cell economy. Ajl \& Werkman $(1948,1949)$ showed that a number of compounds known to participate in the cycle partially abolished the carbon dioxide requirement of cultures grown both aerobically and anaerobically. Dagley, Dawes \& Morrison $(1949,1950 a)$ showed that small additions of these compounds or of their related amino-acids accelerated the growth of $A$. aerogenes in a glucose ammonium salt medium having access to normal atmospheric $\mathrm{CO}_{2}$, either by decreasing lag periods or by increasing initial growth rates. The latter observations were, however, not regarded as evidence for the existence of the full cycle in cultures of $A$. aerogenes, since some of the participating compounds retarded growth, and fluoroacetate, which might be expected to stop growth by blocking the cycle, had in fact little effect. The importance of particular members of the cycle (pyruvic, oxaloacetic and $\alpha$-ketoglutaric acids) was emphasized by the identification of alanine, aspartic and glutamic acids in the metabolizing fluids after growth in glucose ammonium salt medium (Dagley, Dawes \& Morrison, 1950b). Baskett \& Hinshelwood (1950) grew A. aerogenes in chemically-defined media with members of the cycle as sole sources of carbon and, from observations on the degree of training necessary to provide maximum rate of growth on each compound, and from the cross-training also achieved, concluded that the cycle represented a highly significant pattern among the carbon compounds supporting growth.

Extensive investigations by Wood, Werkman and their collaborators during the past decade have elucidated many relationships between pyruvic, oxalo- 
acetic, malic, fumaric, succinic and acetic acids in bacterial metabolism. However, this significance is not confined to the problem of assessing the part played by the tricarboxylic acid cycle in these systems. As Barron (1943) pointed out, pyruvic acid is the hub from which radiates a great variety of metabolic activities; and training to metabolize various carbon sources may, for example, be interpreted by reference to the ease with which cultures achieve a production of pyruvate adequate for growth requirements. In the present work we have related the growth of $A$. aerogenes on various single carbon sources with the rate at which it produces pyruvic acid from them and with its ability to oxidize these substrates completely.

\section{EXPERIMENTAL}

The organism used throughout this work was $A$. aerogenes N.C.T.C. 418. Media were prepared from the following stock solutions: solution $\mathrm{A}, 9 \mathrm{~g} . \mathrm{KH}_{2} \mathrm{PO}_{4}$, 2 g. $\left(\mathrm{NH}_{4}\right)_{2} \mathrm{SO}_{4} /$ l. glass-distilled water, and adjusted to $\mathrm{pH} 7 \cdot 1$; solution $\mathrm{B}$, 9 g. $\mathrm{KH}_{2} \mathrm{PO}_{4} / \mathrm{l}$, pH $7 \cdot 1 ; 1 \%(\mathrm{w} / \mathrm{v})$ solutions of carbon compounds (glucose or organic acids), the $\mathrm{pH}$ of the latter being adjusted to $7 \cdot 1$ with $\mathrm{NaOH} ; 10 \%$ $\left(\mathrm{w} / \mathrm{v}\right.$ ) solution of $\mathrm{MgSO}_{4} \cdot 7 \mathrm{H}_{2} \mathrm{O}$. Solutions were sterilized separately and mixed on cooling. Media for training were made up in Pyrex boiling tubes $(6 \times 1$ in.) from $15 \mathrm{ml}$. solution $\mathrm{A}, 10 \mathrm{ml}$. solution of carbon source and $0 \cdot 1 \mathrm{ml} . \mathrm{MgSO}_{4}$ solution, incubated at $37^{\circ}$ and aerated with a stream of sterile air. At least ten serial subcultures were given in training a particular strain to metabolize a given carbon compound. Methods of obtaining growth curves and precautions necessary to ensure reproducibility have already been described (Dagley, Dawes \& Morrison, $1950 a, c)$. Washed bacterial suspensions were prepared by harvesting after growth in the defined media and washing three times with solution B. Certain experiments with washed suspensions were carried out in large Pyrex tubes $\left(8 \times 1 \frac{1}{2}\right.$ in.).

Pyruvic acid was determined by the toluene extraction method of Friedemann \& Haugen (1943). A calibration curve was prepared with freshly distilled pyruvic acid using a Spekker photoelectric absorptiometer with Ilford filters (neutral $\mathbf{H} 508$ and green OG $\mathbf{1}$ ).

Oxygen uptakes were measured with the conventional Warburg apparatus.

\section{RESULTS}

\section{Production of pyruvate during growth}

Media containing $15 \mathrm{ml}$. solution A, $0 \cdot 1 \mathrm{ml} .10 \%(\mathrm{w} / \mathrm{v}) \mathrm{MgSO}_{4} \cdot 7 \mathrm{H}_{2} \mathrm{O}$ and $10 \mathrm{ml}$. of a $1 \%(\mathrm{w} / \mathrm{v})$ solution of the appropriate carbon source were inoculated with $0.1 \mathrm{ml}$. of a culture which had grown, after training, in an aerated defined medium containing the same source of carbon. The sources of carbon were the following organic acids : malic, lactic, citric, fumaric, succinic and acetic. The pyruvic acid concentrations of the culture fluids were estimated during growth on $5 \mathrm{ml}$. samples of culture withdrawn at intervals and centrifuged rapidly. The results are shown in Fig. 1, where pyruvate concentrations are plotted against the logarithms of the corresponding bacterial populations in order to 
effect a comparison between cultures growing at different rates and to different populations. Growth curves showing sharply defined growth and stationary phases were obtained as described previously (Dagley et al. $1950 a, c$ ). It is seen that the rise in pyruvate concentration during growth was succeeded by a sharp fall when the stationary phase was reached, although in the case of succinate and acetate cultures the amount of pyruvate formed at any stage was barely detectable. We have already reported similar variation in pyruvate concentration in aerated glucose ammonium salt media (Dagley et al. 1950b).

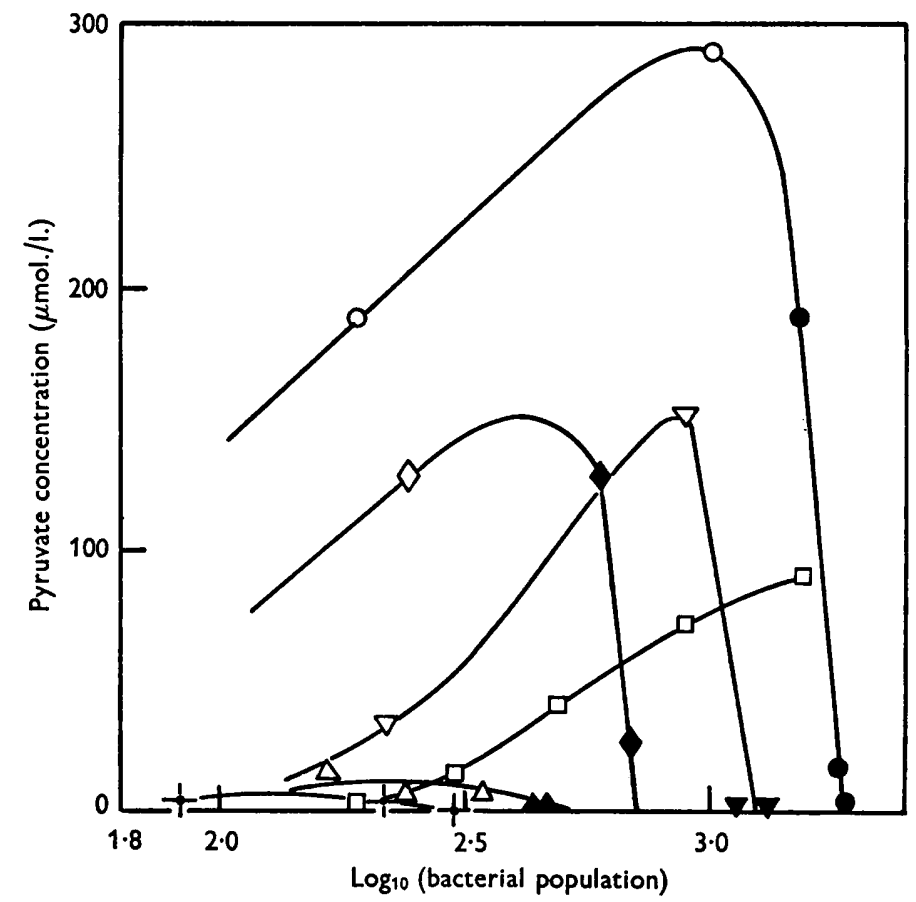

Fig. 1. Pyruvate production during growth on various organic acids : malic, $O$; lactic, $\diamond$; citric, $\nabla$; fumaric, $\square$; succinic, $\triangle$; acetic, - -. Blacked-in symbols indicate values in stationary phase.

\section{Production of pyruvate by washed bacterial suspensions from various substrates}

If pyruvate is an essential intermediate in processes regulating cell division its accumulation during the logarithmic phase may be due to a rate of production in excess of the requirements of the cells, and its disappearance in the stationary phase to exhaustion of the substrate from which it arose. To demonstrate definite pyruvate production from acetate and succinate the ammonium salt was omitted from the medium, and washed cells were used so that pyruvate might accumulate, utilization in cell division being precluded. Under these conditions it was immediately possible to demonstrate the production of pyruvate from acetate and succinate. The investigation was then extended as follows. Washed bacterial suspensions were prepared of cells trained to 
metabolize glucose, succinate, fumarate, malate or acetate, and each batch of cells was then tested for its ability to produce pyruvate. Five sets of large tubes were set up, each containing $40 \mathrm{ml}$. solution $\mathrm{B}, 0.4 \mathrm{ml} .10 \%(\mathrm{w} / \mathrm{v})$ $\mathrm{MgSO}_{4} \cdot 7 \mathrm{H}_{2} \mathrm{O}$ solution; equimolar solutions of the various carbon sources were used, $40 \mathrm{ml}$. per tube being added to the respective sets. When the $20 \mathrm{ml}$. of cell suspension to be tested had been added, the concentration of substrate was $0.028 \mathrm{M}$ in every case. Each tube was then aerated at $37^{\circ}$ by a stream of sterile air at five bubbles per second, and at suitable intervals $5 \mathrm{ml}$. samples were withdrawn, rapidly centrifuged and the pyruvate concentrations of the supernatants determined. Curves for the development of pyruvate concentration with time were obtained for each suspension; those for cells trained to succinate are given in Fig. 2. From such curves the rates of increase of pyruvate concentration were obtained, and in Table 1 are expressed in each case relative to the rate in acetate.

\section{Table 1. Relative rates of pyruvate production by cells trained to metabolize various sources of carbon}

(Figures in brackets give actual pyruvate production from acetate, in $\mu \mathrm{mol} . / \mathrm{l} . / \mathrm{hr}$., for the different batches of cells.)

\begin{tabular}{|c|c|c|c|c|}
\hline \multirow{3}{*}{$\begin{array}{l}\text { Substrates to which } \\
\text { cells were trained }\end{array}$} & \multicolumn{4}{|c|}{ Substrates against which cells were tested } \\
\hline & Malate & Fumarate & Succinate & Acetate \\
\hline & \multicolumn{4}{|c|}{ Relative rates of pyruvate production } \\
\hline Glucose & 20 & 4 & 3 & $1(7)$ \\
\hline Malate & 23 & 13 & 5 & $1(11)$ \\
\hline Fumarate & 15 & 12 & 9 & 1 (15) \\
\hline Succinate & 45 & $\mathbf{2 4}$ & 9 & $1(7)$ \\
\hline Acetate & $\mathbf{5}$ & 1 & 1 & $1(80)$ \\
\hline
\end{tabular}

It is seen that, in general, the pyruvate production from acetate was slower than from any other substrate. Only in the case of those cells which had been trained to acetate was the rate of production comparable with the rest.

Towards the end of each experiment the medium was completed (for growth) by the addition of $1 \cdot 2 \mathrm{~g}$. $\left(\mathrm{NH}_{4}\right)_{2} \mathrm{SO}_{4} / \mathrm{l}$. In every case this addition resulted either in a fall of pyruvate concentration or in the arrest of the steady rise which was occurring prior to the addition. When there was a definite fall in pyruvate concentration, turbidity measurements indicated that cell division had begun.

Inocula of $0.1 \mathrm{ml}$. of suspensions of washed cells trained to the various substrates were tested for their ability to grow in $25 \mathrm{ml}$. lots of media, each containing respectively one substrate as sole carbon source. We confirmed the observations of Baskett \& Hinshelwood (1950) that only cells trained to acetate were able to utilize this compound readily, and found that adaptation to earlier members of the series (acetate, succinate and fumarate) resulted in adaptation to a later member but not to an earlier one. 


\section{Effect of different substrate concentrations}

In the foregoing experiments with washed cells, the rates of pyruvate production were approximately linear. In order to ascertain whether a maximum pyruvate concentration might eventually be reached, thicker suspensions of

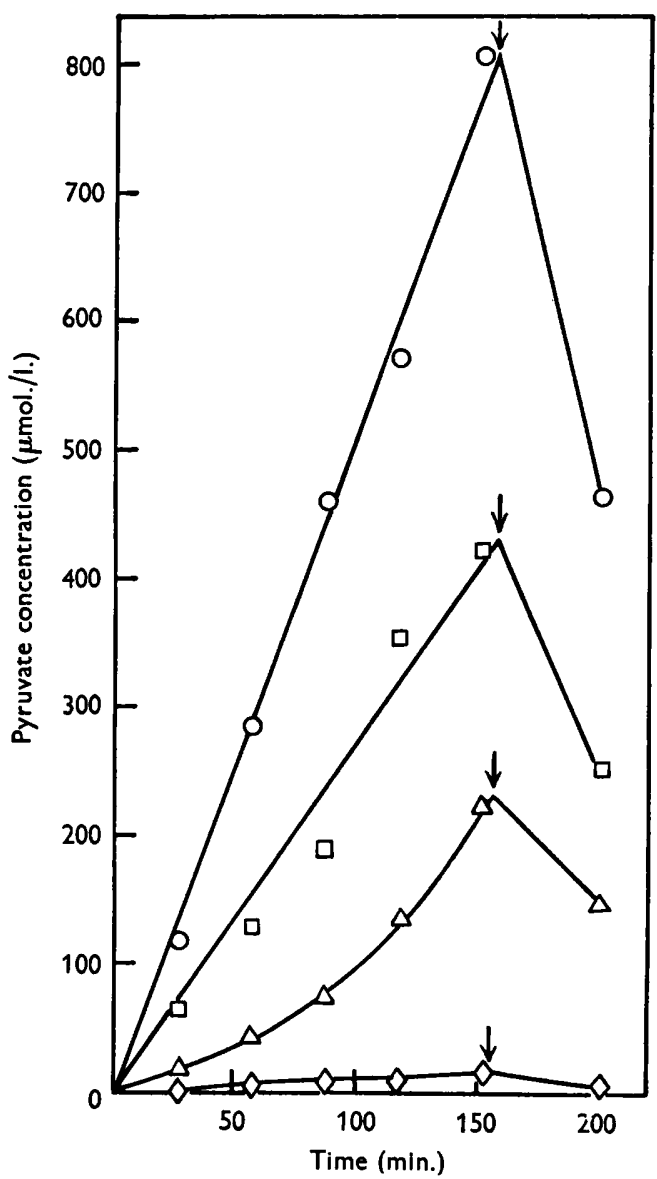

Fig. 2. Pyruvate production by non-proliferating suspensions from various organic acids: malic, $O$; fumaric, $\square$; succinic, $\triangle$; acetic, $\diamond$. Arrows indicate addition of $1 \cdot 2 \mathrm{~g}$. $\left(\mathrm{NH}_{4}\right)_{2} \mathrm{SO}_{4} /$.

higher activities were used and substrate concentrations were varied. Curves for the production of pyruvate from succinate at various concentrations by cells trained to succinate are given in Fig. 3. Curves of similar form have also been obtained for other substrates.

Although the pyruvate concentration reaches a higher maximum the higher the concentration of substrate, no stoichiometrical relationship exists. Thus in Fig. 3, at initial succinate concentrations of $2060,6180,10,300$ and $14,420 \mu \mathrm{mol}$./1., the respective maximum pyruvate concentrations are 57, 323, 630 and $940 \mu \mathrm{mol} . / 1$. When the cells are aerated in phosphate buffer with pyruvate, the 
latter is rapidly decomposed. For example, a concentration of $7600 \mu \mathrm{mol}$. pyruvate/l. was decreased to $150 \mu \mathrm{mol}$./1. in $50 \mathrm{~min}$. These facts indicate that the accumulation of pyruvate in the medium is the result of a rate of production in excess of the rate of decomposition, a maximum being attained when the rates are equal, due to the fall in concentration of the initial substrate and the increase in concentration of the pyruvate.

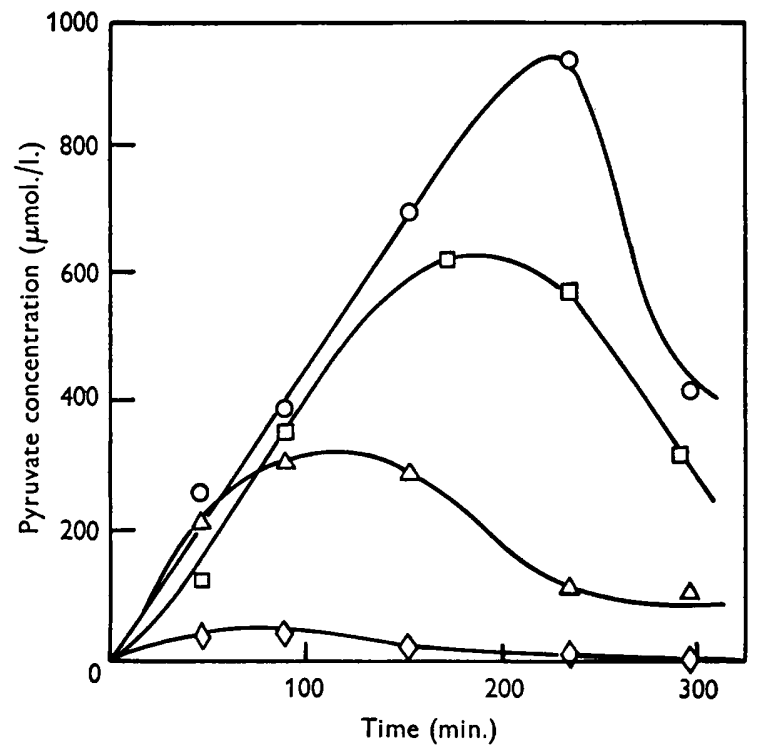

Fig. 3. Pyruvate production by non-proliferating suspensions from succinic acid at various initial concentrations $(\mathrm{mM}): \mathbf{2} \cdot 06, \diamond ; 6 \cdot 18, \triangle ; 10 \cdot 30, \square ; 14 \cdot 42, \bigcirc$.

\section{Rates of oxidation and pyruvic production}

Non-proliferating cell suspensions of many micro-organisms, including $A$. aerogenes, have been shown to be capable of oxidizing to completion the substrates under investigation, except for a proportion which is assimilated (see Clifton, 1946). Measurement of the $\mathrm{O}_{2}$ uptake of cells trained to fumarate, with fumarate, succinate and acetate as equimolar $(0.028 \mathrm{M})$ substrates in the Warburg apparatus, gave values of 77,72 and $56 \mu \mathrm{l} . / 60 \mathrm{~min}$. respectively. The same cell suspension aerated with the same substrates in boiling tubes gave, respectively, the following rates of pyruvate production: 281, 236 and $15 \mu \mathrm{mol} . / 1 . / 60 \mathrm{~min}$.

Bearing in mind that the theoretical $\mathrm{O}_{2}$ uptakes for fumarate, succinate and acetate are in the ratio $6: 7: 4$, it is clear that the difficulty experienced by fumarate-trained cells in producing pyruvate from acetate is not related to the rate at which they oxidize the substrate to completion.

\section{DISCUSSION}

Baskett \& Hinshelwood (1950) found that cells trained to glucose could adapt with increasing difficulty, as reflected in the training they required, to the series malate, fumarate, succinate and acetate, and we have found that for a 
given batch of cells, except those trained to acetate, the rates of pyruvate production from these substrates by washed suspensions followed the order, malate $>$ fumarate $>$ succinate $>$ acetate. Training to grow on acetate, however, also stimulated ability to produce pyruvate from acetate, and it appears that cell division is related to the ability to synthesize this key metabolite at a rate greater than its rate of decomposition. The function of pyruvate as a growth intermediate is shown by the addition of ammonia to complete the medium,

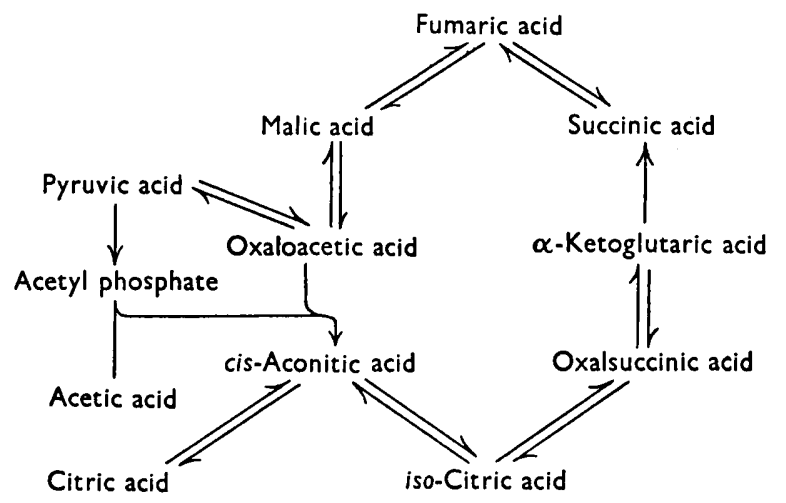

Fig. 4. The tricarboxylic acid cycle.

when the cells immediately draw on the accumulated pyruvate for their growth requirements. Glucose and malate, which are rapidly decomposed to pyruvate by cell suspensions, evidently permit pyruvate production in excess of growth requirements in the logarithmic phase, but in experiments with cultures growing on succinate and acetate, with lower rates of production of pyruvate by washed cells, pyruvate was barely detectable in the metabolizing fluids.

The complete oxidations of malate, fumarate and succinate probably proceed by way of pyruvate, and it is of general interest that the curves of Fig. 3 take the form predicted for an intermediate in a reaction-sequence and exhibit maxima dependent upon initial substrate concentration as the kinetics of such a system require (Glasstone, 1946).

If the tricarboxylic acid cycle (Fig. 4) be accepted as the mechanism for the complete oxidation of these substrates, the maxima in Fig. 3 might correspond to the complete establishment of the cycle. This mechanism, however, is not compatible with our findings, for the following reasons. Washed suspensions of acetate-trained cells give a linear production of pyruvate immediately on aeration. In phosphate buffer alone, with no added source of carbon, no pyruvate is produced and no significant amount of oxaloacetic acid (its precursor in the cycle) can, therefore, be present. An accumulation of pyruvate in the early stages requires either the production of oxaloacetate in excess of the requirements of the cycle, or the presence of appreciable amounts of oxaloacetate initially. The latter, as we have seen, is ruled out, and it is impossible for oxaloacetate to accumulate solely by the reactions summarized in Fig. 4 and, at the same time, to fulfil the demand of the cycle that one oxalo- 
acetate molecule be consumed for each molecule formed from acetate. Furthermore, although the cycle is a respiratory mechanism, we found that fumaratetrained cells were able to oxidize succinate, fumarate or acetate at comparable rates but had great difficulty in producing pyruvate from acetate, although they did so readily from the other two substrates. These observations present no difficulty of interpretation if the substrate is oxidized via pyruvate and acetate by a non-cyclic process, and if the conversion of acetate to pyruvate takes place by an independent mechanism which only training to acetate can fully develop. Although Baskett \& Hinshelwood (1950) concluded that the cycle represented a highly significant pattern among the carbon compounds used in their studies of training, they did not claim the complete operation of the cycle as the mechanism of bacterial respiration. Indeed, they concluded that 'some stretches appear to be utilized only to a small extent by cells grown in glucose', and we may conclude from our studies that the sequences resulting in the formation of pyruvic acid are of prime importance. When acetate is the substrate a mechanism such as that of the cycle, which involves prior reaction with a product of respiration, is not acceptable, and a possible alternative is that suggested by Slade \& Werkman (1943) in which succinate, and hence pyruvate, can be produced by the reaction between two molecules of acetic acid.

\section{REFERENCES}

AJu, S. J. \& Werkman, C. H. (1948). Replacement of $\mathrm{CO}_{2}$ in heterotrophic metabolism. Arch. Biochem. 19, 483.

AJu, S. J. \& Werkman, C. H. (1949). Anaerobic replacement of carbon dioxide. Proc. Soc. exp. Biol., N.Y., 70, 522.

Barron, E. S. G. (1943). Mechanisms of carbohydrate metabolism. An assay on comparative biochemistry. Adv. Enzymol. 3, 149.

Baskett, A. C. \& Hinshelwood, C. N. (1950). The utilization of carbon sources by Bact. lactis aerogenes. I. General survey. Proc. roy. Soc. B, 136, 520.

Curfton, C. E. (1946). Microbial assimilations. Advances in Enzymology, 6, 269.

Dagley, S., Dawes, E. A. \& Morrison, G. A. (1949). Influence of amino-acids, and compounds in the Krebs oxidation cycle, on 'early lag'. Biochem. J. 45, xxvi.

Dagley, S., Dawes, E. A. \& Morrison, G. A. (1950 a $)$. Factors influencing the early phases of growth of Aerobacter aerogenes. J. gen. Microbiol. 4, 437.

Dagley, S., Dawes, E. A. \& Morrison, G. A. $(1950 b)$. Production of amino acids in synthetic media by Escherichia coli and Aerobacter aerogenes. Nature, Lond., $165,437$.

Dagley, S., Dawes, E. A. \& Morrison, G. A. $(1950 \mathrm{c})$. Inhibition of growth of Aerobacter aerogenes: the mode of action of phenols, alcohols, acetone and ethyl acetate. J. Bact. 60, 369.

Friedemann, T. E. \& Haugen, G. E. (1943). Pyruvic acid. II. The determination of keto acids in blood and urine. J. biol. Chem. 147, 415.

Glasstone, S. (1946). Textbook of Physical Chemistry, 2nd. ed., p. 1077. New York: Van Nostrand Incor.

Slade, H. D. \& Werkman, C. H. (1943). Assimilation of acetic and succinic acids containing heavy carbon by Aerobacter indologenes. Arch. Biochem. 2, 97.

(Received 6 December 1950) 